\title{
Alzheimer Research Forum Discussion: Gain or Loss of Function - Time to Shake up Assumptions on $\gamma$-Secretase in Alzheimer Disease?
}

\section{Introduction by Gabrielle Strobel}

If in your own mind you had Peter Davies pigeonholed as a tau researcher, think again. While Davies' penchant for skepticism and doubt has established him as an occasional thorn in the side of a dominant amyloid hypothesis, his work on tau is not the only avenue that got him there.

Like many researchers today, Davies actively studies both major arms of Alzheimer disease pathology, and it is the amyloid side that drew his questioning gaze to the topic of the present discussion. Last month, researchers led by Bart de Strooper, at K.U. Leuven, Belgium, and colleagues in Germany, reported their analysis of how five different clinical presenilin 1 mutations and one presenilin 2 mutation affect the function of the $\gamma$ secretase complex. These scientists were pursuing the question of whether the mutations lead to a toxic gain of function (i.e., more $\mathrm{A} \beta 42$ production), or perhaps also to a partial loss of function - an idea that may seem murky, unwieldy, and inconveniently counterintuitive but that has nonetheless been picking up some steam with recent studies.

First author Mostafa Bentahir and colleagues reported a mixed picture. All the examined mutations compromised the secretase's ability to process APP at a recently discovered epsilon cleavage site, while APP cleavage at the $\gamma$ site varied from mutation to mutation. Some mutations led to more $\mathrm{A} \beta 42$ production but others led to a drop in $\mathrm{A} \beta 40$ production, and it was this latter finding, together with the loss of epsilon cleavage, that caught Davies' eye. "Once in a blue moon, a paper comes out that really changes my thinking in an important way. That just happened," Davies wrote to ARF.

Soon after, a second study fueled the issue further. First author Samir Kumar-Singh and colleagues, led by ARF advisor Christine Van Broeckhoven at the University of Antwerp, Belgium, developed a new method to measure FAD effects on $\gamma$-secretase. Their motivation partly was to develop a robust tool for predicting the clinical severity of a given FAD mutation in patients but, lo and behold, they similarly found that of nine FAD mutations examined, all consistently lowered $\mathrm{A} \beta 40$ levels whereas only some drove up $\mathrm{A} \beta 42$. Kumar-Singh et al. also found that loss of $\mathrm{A} \beta 40$ correlated quite well with the age at which disease began.

All these changes add up to an alteration of the $\mathrm{A} \beta 42 / \mathrm{A} \beta 40$ ratio, which is widely assumed to be a key factor in $\mathrm{AD}$ pathogenesis. Here are some questions to consider: Just how important is it which side tips the ratio? Is this mostly a fine point, because the ratio itself is what has the relevant biological consequences? Or would a selective decrease of $\mathrm{A} \beta 40$ indeed have fundamental implications for pathogenesis, for therapeutic strategies? How about a selective loss of epsilon cleavage? More broadly, should the field pursue APP processing products other than $\mathrm{A} \beta$ with more vigor? Is catalytic activity per se the main Achilles heel of $\gamma$ secretase, or could it be its assembly, or even the way its different substrates dock, and then access that catalytic site? Which of these changes brings on disease? 


\section{Comment by: Peter Davies, Albert Einstein College of Medicine, Bronx, New York, USA \\ Submitted 25 March 2006}

Bart De Strooper and colleagues have just published a paper on the effects of presenilin (PS) mutations on the processing of APP (and other proteins). I think this paper is extremely important, and corroborated by another manuscript currently in press. This work deserves careful deliberation, and to that end I invite my colleagues in the Alzheimer research community to consider the study's implications in this public and collegial forum. My thoughts below serve to jumpstart such a deliberation with the questions the work raised in my mind.

Bentahir et al. take advantage of cell lines lacking both presenilins 1 and 2 ; that serves to eliminate the possible interaction between endogenous and transgenic mutant forms of PS that had muddied the waters in analyzing the effect of the mutations before. The authors replaced the endogenous presenilins with either wild-type or a series of FAD mutant proteins and reported the effect of these replacements on the processing of APP and of three other proteins. In short, their major result is that clinical PS mutations cause a partial loss of function in APP processing, particularly at its epsilon cleavage site, and that this leads to lowering of $\mathrm{A} \beta 40$ more consistently than to increases in $\mathrm{A} \beta 42$.

Many investigators say that PS mutations increase $\mathrm{A} \beta$ production from APP, and some qualify this to say that $\mathrm{A} \beta 42$ is selectively increased, rather than total $\mathrm{A} \beta$. Bentahir et al. show that if one wants to focus on $\mathrm{A} \beta$, then it is really the $\mathrm{A} \beta 42 / \mathrm{A} \beta 40$ ratio that must be measured. Importantly, one must measure separately how each of the ratio's components change to know what is driving the change in the ratio. As reported in the paper, most of the PS mutations decrease $\mathrm{A} \beta 40$, and there is at best a tendency to increase $\mathrm{A} \beta 42$. There is usually a change in ratio but it is not striking, and this is a very different phenomenon than an INCREASE in the amount of $A \beta 42$. The separate study by Kumar-Singh et al. confirms this observation even more strongly, reporting that of nine different FAD PS mutations studied, all markedly lowered $\mathrm{A} \beta 40$, but only half significantly increased $\mathrm{A} \beta 42$ levels.

Different mechanisms of disease must be examined if what we are looking at is a change in ratio driven by a decreased $\mathrm{A} \beta 40$ concentration, rather than a large increase in the amount of $A \beta 42$. This is very significant because many research groups across our field search for mechanisms that increase $\mathrm{A} \beta$ as potential mechanisms of AD. These are attempts to mimic the presumed effects of the presenilin mutations. We look at this in my lab, too, by measuring the effects of various manipulations on the amount of $\mathrm{A} \beta$ produced by cells. We, as well as many others, assume that things that increase $\mathrm{A} \beta$ will promote $\mathrm{AD}$, and things that decrease it will do the opposite.

Many researchers also look for mechanisms to lower $\mathrm{A} \beta$, presuming these will be potential treatments for $\mathrm{AD}$. The papers discussed here show that these assumptions may be dangerous to make. If one did not know that PS mutations caused AD, one would probably not guess it from the effects of these mutations on $\mathrm{A} \beta$ production as reported in the papers, whichever species was measured.

These papers suggest to me that we should be looking for things that alter APP processing to reduce the production of $\mathrm{A} \beta 40$ (perhaps without affecting $\mathrm{A} \beta 42$ or producing a small increase in it) as mechanisms of disease. Such manipulations may better mimic the effects of a presenilin mutation than simple elevation in the total amount of $\mathrm{A} \beta$, or $\mathrm{A} \beta 42$, produced. To me the most striking figure in Bentahir et al. is $3 \mathrm{~b}$, which shows the effects of the presenilin mutations on production of the intracellular carboxyterminal fragment (CTF) of APP. Though the effect of the different mutations on $\mathrm{A} \beta 42$ varied, all mutations examined produced a marked reduction in the amount of the CTF (as compared to wild-type PS1). There is now a great deal of interest in the production of the CTF (also called amyloid intracellular domain, AID or AICD) as another product of $\gamma$-secretase cleavage, and many suggestions about the function of this product, especially as a modulator of gene expression or calcium homeostasis. I think that manipulations that reproduce a similar substantial reduction in production of the CTF should presumably be promoting $\mathrm{AD}$, whatever their diverse effects on $\mathrm{A} \beta$.

When I saw this data for the first time I was concerned. Now looking at it in detail, I am even more convinced that I am attacking this problem the wrong way, and I don't think I am alone in doing so. Many of us rely heavily on measurements of $\mathrm{A} \beta$ to direct us to mechanisms that might promote or suppress AD. This may be very misleading.

It is also of concern that $\gamma$-secretase inhibitors, which also reduce the amount of $\mathrm{A} \beta 40$ and of the $\mathrm{CTF}$, are proposed as treatments for $\mathrm{AD}$. In this aspect, their effects are alarmingly similar to those of the presenilin mutations. Since BACE1 inhibitors will also reduce 
both generation of $\mathrm{A} \beta 40$ and the $\mathrm{CTF}$, their effects may resemble those of PS1 mutations, as well. Has the focus on measurement of $\mathrm{A} \beta$ production led us down the wrong path in AD research? I think we have to seriously consider this question.

Comment by: Nikolaos K. Robakis, Mount Sinai School of Medicine, New York, New York, USA Submitted 28 March 2006

\section{Many Mechanisms to Gain $\mathrm{A} \beta$ and Its Uncertain Role in AD}

Peter's comments are very well taken. Regarding PS1, several papers published within the last 3 to 4 years suggest that certain FAD mutations cause a loss of function at the $\varepsilon$ cleavage site (also catalyzed by the $\gamma$-secretase complex) of many proteins including APP itself [1], cadherins, Notch1, and ephrinB. A theoretical objection against the gain-of-function hypothesis for the PS1 mutations is that it is extremely difficult to imagine biochemical mechanisms that will explain how all FAD mutations distributed throughout the PS1 polypeptide may result in a gain of the same enzymatic activity, namely an increase in the $\gamma$-secretase cleavage. On the other hand, it is easy to imagine how a loss of function can finally appear as a gain. As an example, loss of cleavage function at the $\varepsilon$ site of APP due to FAD mutations, for example, London mutations, may appear as a gain in $\mathrm{A} \beta$ production because this loss may increase the available substrate for cleavage at the $\gamma$ sites.

More important, there is clear experimental evidence in the literature that not all FAD mutations increase $\mathrm{A} \beta$ production (e.g., see the data in [2]). In my own laboratory, we identified at least five FAD mutations out of eight examined that show no increase in either $\mathrm{A} \beta 40$ or 42 (unpublished data). It is thus a clear overstatement to write, as some have, that all FAD mutations increase production of a specific $\mathrm{A} \beta$ isoform.

Similarly, that some PS1 FAD mutations may increase $\mathrm{A} \beta$ does not necessarily imply a gain in $\gamma$ secretase function itself. This could happen more indirectly. In addition to the potential effects of the $\varepsilon$ secretase cleavage mentioned above, PS1, like many other proteins, has other functions. For example, reports from several laboratories show that FAD mutations cause a loss of PS1 function in the PI3K/Akt cell survival pathway in a $\gamma$-secretase-independent manner. A partial loss of Akt activity caused by FAD mutations may result in a gain of GSK-3 activity and in increased tau phosphorylation and apoptosis. Since GSK-3 can stimulate $\mathrm{A} \beta$, a loss of PS1 activity at Akt may appear as a gain of $\gamma$-secretase function. Furthermore, increased apoptotic activity (induced by FAD mutations) can also promote $\mathrm{A} \beta$ production.

I agree with Peter that we need to be concerned about the theory that lower $\mathrm{A} \beta 40$ can be used as a treatment for $\mathrm{AD}$. Indeed, the evidence supporting a primary role for $\mathrm{A} \beta$ or its derivatives (aggregates or amyloid) in the development of $\mathrm{AD}$ is far from conclusive, and many workers have expressed this view in the literature over the last decade [3-6]. Research over the last 20 years has shown that lesions in the proteins of presenilins and APP are important for at least some forms of Alzheimer-type neurodegeneration and dementia. On the other hand, although $\mathrm{A} \beta$ and its derivatives are important for the definition of $\mathrm{AD}$, their role as causative agents of the disorder is less certain.

\section{References}

[1] J.C. Wiley, M. Hudson, K.C. Kanning, L.C. Schecterson and M. Bothwell. Familial Alzheimer's disease mutations inhibit gamma-secretase-mediated liberation of beta-amyloid precursor protein carboxy-terminal fragment, J Neurochem 94 (2005), 1189-1201.

[2] O. Murayama, T. Tomita, N. Nihonmatsu, M. Murayama, X. Sun, T. Honda, T. Iwatsubo and A. Takashima, Enhancement of amyloid beta 42 secretion by 28 different presenilin 1 mutations of familial Alzheimer's disease, Neurosci Lett 265 (1999), 6163.

[3] L. Baki, J. Shioi, P. Wen, Z. Shao, A. Schwarzman, M. GamaSosa, R. Neve and N.K. Robakis, PS1 activates PI3K thus inhibiting GSK-3 activity and tau overphosphorylation: effects of FAD mutations, EMBO J 23 (2004), 2586-2596.

[4] F. Chen, Y. Gu, H. Hasegawa, X. Ruan, S. Arawaka, P. Fraser, D. Westaway, H. Mount and P. St George-Hyslop, Presenilin 1 mutations activate gamma 42-secretase but reciprocally inhibit epsilon-secretase cleavage of amyloid precursor protein (APP) and S3-cleavage of notch, J Biol Chem 277 (2002), 1-6.

[5] A. Georgakopoulos, C. Litterst, E. Ghersi, L. Baki, C.J. Xu, G. Serban and N.K. Robakis, Metalloproteinase/Presenilin1 processing of ephrinB regulates EphB-induced Src phosphorylation and signaling, EMBO J 25 (2006), 1242-1252.

[6] P. Marambaud, P. Wen, A. Dutt, J. Shioi, R. Siman, A. Takashima and N.K. Robakis, A CBP-binding transcriptional repressor produced by the PS1/epsilon-cleavage of N-cadherin is inhibited by PS1 FAD mutations, Cell 114 (2003), 635-645.

Comment by: Takeshi Iwatsubo, University of Tokyo, Tokyo, Japan

Submitted 31 March 2006

A number of mutations in presenilin (PS) 1, 2, or APP genes linked to familial AD (FAD) have been 
shown to increase the ratio of $\mathrm{A} \beta 42 / \mathrm{A} \beta 40$ secreted from cells, or in the brains of transgenic mice overexpressing these mutant genes. As pointed out by Bentahir et al. and Kumar-Singh et al., the absolute levels of secreted $\mathrm{A} \beta 40$ are often significantly decreased, while those of $\mathrm{A} \beta 42$ are not robustly changed, resulting in an increase in the $\mathrm{A} \beta 42 / \mathrm{A} \beta 40$ ratio.

$\gamma$-secretase cleaves its substrates at multiple sites within the transmembrane domain; the $\gamma$-cleavages of APP take place at positions 40 or 42 , and the $\gamma$ or $\varepsilon$ cleavage to produce AICD at position 49 . The catalytic site of $\gamma$-secretase comprising the two transmembrane aspartate residues appears to attack the scissile bonds of substrates (which are predicted to form $\alpha$ helices) at a combination of multiple sites. This determines the levels of products and their relative ratios at a constant level, that is, $\varepsilon$-cleavage to produce AICD at position 49 and $\gamma$-cleavage to yield $\mathrm{A} \beta 40$ being predominant. FAD mutations cause substitutions of single amino acid residues within PS polypeptide, and these substitutions shift the preferred cleavage sites from positions 40 and 49 to 42 , facilitating production of a more aggregable $\mathrm{A} \beta 42$ species. The precise molecular mechanism whereby FAD mutations cause the "shift" in the cleavage sites by $\gamma$-secretase remains unclear, but single amino acid substitutions in PS may subtly distort its three-dimensional structure and alter the cleavage patterns.

It is currently unknown whether reduction in $\mathrm{A} \beta 40$ cleavage either increases the supply of substrates to the $\gamma 42$-secretase within an identical protease complex or to a subcellular compartment that preferentially produces $\mathrm{A} \beta 42$, or whether, alternatively, all the changes take place simultaneously. In this regard, the pathological phenotype caused by FAD mutations, that is, increase in $\mathrm{A} \beta 42$ and decrease in $\mathrm{A} \beta 40$, could well be interpreted either as "gain of abnormal function" that alters the function of PS (as $\gamma$-secretase), or alternatively as "partial loss of function" when we consider the production of the major cleavage products, that is, $\mathrm{A} \beta 40$ or AICD, as its "normal" function.

Which, then, is the pathogenic phenomenon in the brains of patients with $\mathrm{AD}$, especially FAD with a PS mutation: reduction in $\mathrm{A} \beta 40$, reduction in $\mathrm{AICD}$, or increase in $A \beta 42$ ? We have to keep in mind that earlyonset FAD is an autosomal-dominant disease, in which patients harbor one mutant allele together with one wild-type (wt) allele. Indeed, heterozygous PS1 KO mice that carry one copy of wt PS1, or knock-in mice that harbor one copy each of mutant and wt PS1 (Wang $\mathrm{R}$ et al., J Biol Chem, in press) showed only a mod- erate decrease in $\gamma$-secretase activity and $\mathrm{A} \beta 40$ level compared to those with only one copy of mutant PS1. Moreover, FAD patients do not show any developmental abnormalities caused by decreased Notch signaling. Collectively, the levels of $\mathrm{A} \beta 40$ or AICD/NICD production in the brains of FAD patients may not be significantly decreased, although that of $\mathrm{A} \beta 42$ should be increased. Therefore, the significant reduction in A $\beta 40$ observed in cellular experiments may reflect the lack of wt PS1 (by KO or "replacement" of wt PS1 by overexpression), and may not be causally related to the development of $\mathrm{AD}$ in people.

Nonetheless, we do not know whether the chronic reduction of $\gamma$-secretase activity at a subthreshold level may be related to any of the manifestations of AD (especially those unrelated to amyloid- $\beta$ deposition), an issue we may have to clarify.

Comment by: Hyoung-gon Lee ${ }^{\mathrm{a}}$, Akihiko Nunomura $^{\mathrm{b}}$, George Perry ${ }^{\mathrm{a}, \mathrm{c}}$, Mark A. Smith ${ }^{\mathrm{a}}$

${ }^{a}$ Case Western Reserve University, Cleveland, Ohio, USA

${ }^{\mathrm{b}}$ Asahikawa Medical College, Asahikawa, Japan ${ }^{\mathrm{c} U n i v e r s i t y ~ o f ~ T e x a s ~ a t ~ S a n ~ A n t o n i o, ~ S a n ~ A n t o n i o, ~}$ Texas, USA

Submitted 31 March 2006

\section{Less Amyloid- $\beta$ Equals More Disease}

The relationship between amyloid- $\beta$ and Alzheimer disease may finally have hit the "irreconcilable differences" stage. Things have been rocky ever since revelations of a spatial, temporal, and pathologic separation between the parties including: 1) the weak relation between amyloid- $\beta$ and disease state $[1,2] ; 2$ ) the very high amyloid- $\beta$ loads often seen in cognitively intact old people [3]; and 3) that transgenic animal models with supraphysiological amyloid- $\beta$ levels show little/no neuronal loss [4]. Now, perhaps the most damning evidence to date: Mutations known to cause Alzheimer disease actually reduce the overall levels of amyloid- $\beta$ [5]. While these findings are at odds with the amyloid hypothesis [6,7], they are consistent with an alternate amyloid hypothesis [8] whereby amyloid$\beta$ serves as a protective molecule produced in response to oxidative or other insults $[9,10]$. Importantly, mutations shown to reduce levels of amyloid- $\beta$ [5] would be predicted to cause increased oxidative insult, and this is indeed the case in vivo in familial Alzheimer disease [11]. Could it be that less amyloid- $\beta$ equals more disease? 


\section{References}

[1] P. Delaere, C. Duyckaerts, J.P. Brion, V. Poulain and J.J. Hauw, Tau, paired helical filaments and amyloid in the neocortex: a morphometric study of 15 cases with graded intellectual status in aging and senile dementia of Alzheimer type, Acta Neuropathol (Berl) 77 (1989), 645-653.

[2] P. Giannakopoulos, F.R. Herrmann, T. Bussiere, C. Bouras, E. Kovari, D.P. Perl, J.H. Morrison, G. Gold and P.R. Hof, Tangle and neuron numbers, but not amyloid load, predict cognitive status in Alzheimer's disease, Neurology 60 (2003), 1495-1500.

[3] H. Crystal, D. Dickson, P. Fuld, D. Masur, R. Scott, M. Mehler, J. Masdeu, C. Kawas, M. Aronson and L. Wolfson, Clinicopathologic studies in dementia: nondemented subjects with pathologically confirmed Alzheimer's disease, Neurology 38 (1988), 1682-1687.

[4] M.C. Irizarry, F. Soriano, M. McNamara, K.J. Page, D. Schenk, D. Games and B.T. Hyman, Abeta deposition is associated with neuropil changes, but not with overt neuronal loss in the human amyloid precursor protein V717F (PDAPP) transgenic mouse, J Neurosci 17 (1997), 7053-7059.

[5] M. Bentahir, O. Nyabi, J. Verhamme, A. Tolia, K. Horre, J. Wiltfang, H. Esselmann and B. de Strooper, Presenilin clinical mutations can affect gamma-secretase activity by different mechanisms, J Neurochem 96 (2006), 732-742.

[6] J.A. Hardy and G.A. Higgins, Alzheimer's disease: the amyloid cascade hypothesis, Science 256 (1992), 184-185. Review.

[7] J. Hardy and D.J. Selkoe, The amyloid hypothesis of Alzheimer's disease: progress and problems on the road to therapeutics, Science 297 (2002), 353-356. Review. Erratum in: Science 297 (2002), 2209.

[8] H.G. Lee, X. Zhu, A. Nunomura, G. Perry and M.A. Smith, Amyloid beta: the alternate hypothesis, Curr Alzheimer Res 3 (2006), 75-80.

[9] S.D. Yan, S.F. Yan, X. Chen, J. Fu, M. Chen, P. Kuppusamy, M.A. Smith, G. Perry, G.C. Godman, P. Nawroth et al., Nonenzymatically glycated tau in Alzheimer's disease induces neuronal oxidant stress resulting in cytokine gene expression and release of amyloid beta-peptide, Nat Med 1 (1995), 693699.

[10] A. Nunomura, G. Perry, G. Aliev, K. Hirai, A. Takeda, E.K. Balraj, P.K. Jones, H. Ghanbari, T. Wataya, S. Shimohama, S. Chiba, C.S. Atwood, R.B. Petersen and M.A. Smith. Oxidative damage is the earliest event in Alzheimer disease, $J$ Neuropathol Exp Neurol 60 (2001), 759-767.

[11] A. Nunomura, S. Chiba, C.F. Lippa, P. Cras, R.N. Kalaria, A. Takeda, K. Honda, M.A. Smith and G. Perry, Neuronal RNA oxidation is a prominent feature of familial Alzheimer's disease, Neurobiol Dis 17 (2004), 108-113.

Comment by: Hui Zheng, Baylor College of Medicine, Houston, Texas, USA

Submitted 5 April 2006

The two papers cited above employ the use of cell cultures and human samples to study the pathogenic mechanisms of PS FAD mutations. Complementing these studies and using transgenic mouse models, we report that overall reduced $\mathrm{A} \beta 40$ and PS-dependent processing is the underlying mechanism for increased $\mathrm{A} \beta 42 / \mathrm{A} \beta 40$ ratio and accelerated amyloid pathology in two strains of PS1-related transgenic mice $[1,2]$. Our studies support a partial loss-of-function activity by the PS FAD mutations.

\section{References}

[1] R. Wang, B. Wang, W. He and H. Zheng, Wild-type presenilin 1 protects against Alzheimer's disease mutation-induced amyloid pathology, J Biol Chem (2006).

[2] Y. Deng, L. Tarassishin, V. Kallhoff, E. Peethumnongsin, L. Wu, Y-M. Li and H. Zheng, Deletion of Presenilin 1 Hydrophilic Loop Sequence Leads to Impaired gamma-secretase Activity and Exacerbated Amyloid Pathology, J Neurosci 26 (2006), 3845-3854.

\section{Comment by: Bart De Strooper, Katholieke Uni-} versiteit Leuven, Leuven, Belgium

Submitted 6 April 2006

I appreciate very much the thoughtful comments on our work by Dr. Davies and the other scientists concerning its implications for the current thinking on AD. The primary question in our manuscript [1] is, however, biochemical in nature, that is, how do mutations in presenilin affect $\gamma$-secretase proteolytic activity. Reconstituted knockout fibroblasts are a fine tool to perform this type of experiment because one avoids interference by the wild-type molecules. The conclusion of the work is clear: Clinical mutations in PS cause a loss of $\gamma$-secretase (enzymatic) function. What our findings imply for the understanding of the pathogenesis of Alzheimer disease is, however, less clear to me. I would therefore like to provide some thoughts here regarding three issues raised in the ongoing discussions.

\section{Concerning the Effect of the PS1 FAD Mutations} on Total $A \beta$ in Brain

The effect of a partial loss-of-function allele in the context of three other healthy alleles (one PS1 and two PS2) is quite difficult to predict, especially in the in vivo situation where clearance factors, compensatory mechanisms, and additional pathogenetic factors considerably complicate the picture. Likely, a FAD mutation in one single PS1 allele will not dramatically affect the total $\mathrm{A} \beta$ peptide production in brain since the healthy PS alleles will compensate for the partial loss of the diseased PS function. It is also possible that 
in vivo (in contrast to the more acute experiments we performed in fibroblasts in vitro), the APPCTF substrate accumulates as a consequence of the partial loss of function of the FAD-PS1, which then would lead to a new steady-state situation with more substrate driving $\mathrm{A} \beta$ peptide generation. Compared to the normal situation, this could theoretically result in quantitatively similar levels of $\mathrm{A} \beta$ peptide but qualitatively higher amounts of the $\mathrm{A} \beta 42$ variant. Even a small relative increase of this $\mathrm{A} \beta 42$ peptide could critically affect $\mathrm{A} \beta$ amyloid deposition and generation of the putative toxic $\mathrm{A} \beta$ oligomer form. The minimal conclusion is that it is very difficult to predict the final outcome in brain based on our observations in reconstituted fibroblasts alone. A very recent and elegant publication by Hui Zheng (JBC, online) provides experimental support for these ideas.

2. Concerning the Role of Loss of Function of PS in the Pathogenesis of $A D$

Does our work provide evidence that loss of presenilin function contributes in other ways to AD? We cannot exclude the possibility that loss of presenilin function contributes to the early and fast development of $\mathrm{AD}$ in patients with PS mutations. However, it seems to me very unlikely that partial loss of PS function also contributes to the sporadic forms of AD or to the familial forms caused by APP mutations. In fact, even for the families with PS mutations I doubt whether loss of PS function contributes in other ways than deficient APP processing to the disease process. Let's consider a different type (than FAD mutations) of loss of PS function mutations, that is, the entire loss of a PS1 allele as seen in heterozygote PS1+/- mice. These mice display no phenotype, at least in the animal house, because the partial loss of Notch signaling is compensated by the healthy PS alleles. In these animals no alterations are observed in the spectrum of $\mathrm{A} \beta$ peptides because the remaining alleles produce normal proteases. Hence, a paradox: The entire loss of function of one PS allele is not harmful, while a partial loss of activity of one allele as seen in FAD patients causes AD. The conclusion is obviously that loss of PS function on its own does not cause $\mathrm{AD}$, and that FAD mutations act only indirectly via the incomplete digestion of APP and the generation of a more toxic $\mathrm{A} \beta$ peptide. Total loss of function alleles of PS can also cause a spectrum of diseases depending on the organ and the time of development where the total knockout is induced. These diseases have been intensively investigated in mice and vary among cancer, immune disorders, embryonic lethality, and even neurodegeneration. However, in none of these diseases are amyloid deposits or neuronal tangles observed, further raising doubts that loss of presenilin function, other than its role in APP processing, is important for the development of AD.

3. Is the Amyloid Hypothesis Dead?

I feel it quite premature to declare that the amyloid hypothesis is dead as some of the participants in the debate seem to propose. The alternative hypotheses consider either presenilin or other factors as central and $\mathrm{A} \beta$ peptides as peripheral to the disease process. It is difficult to see how presenilin dysfunction could cause sporadic AD and especially familial AD with APP mutations. Hypotheses that do not take into account $\mathrm{A} \beta$ peptide toxicity do not explain how, for instance, the Swedish APP mutation causes AD. This mutation increases absolute amounts of $\mathrm{A} \beta$ peptide but does not affect, as far as we know, presenilin function. The amyloid hypothesis has the big advantage that it accommodates APP mutations, APP gene duplications, presenilin mutations, and the presence of amyloid plaques in genetic as well as in sporadic AD. It is clear that tangles have only recently been incorporated in the hypothesis, downstream of $\mathrm{A} \beta$ peptide toxicity. Putting tangles downstream of $\mathrm{A} \beta$ is consistent with the genetic mutations in tau (frontotemporal dementia linked to chromosome 17) that cause tangles but not amyloid plaques. Of course, the amyloid hypothesis will evolve over the years to further incorporate new experimental findings. The latest addition - the concept of small $\mathrm{A} \beta$ oligomers as toxic intermediates helps to explain why not only increased levels of $\mathrm{A} \beta$ peptides, but also changes in their biophysical properties, could cause disease. The amyloid hypothesis accounts for many more experimental data than any other theory in the Alzheimer literature and provides, therefore, a very strong theoretical frame for Alzheimer research. I do not believe that further in vitro experiments will be able to really challenge this framework. The only way forward now is to perform the critical experiments in the clinic by treating patients with anti-A $\beta$ peptide therapies. It is indeed possible 
that we have been looking in a biased way to the evidence accumulating over the last 20 years, and it is even likely that the amyloid hypothesis covers only part of the truth. However, as with the cholinergic hypothesis, bringing medication to patients is the only way to test this question.

In the meantime, I personally remain convinced that blocking $\mathrm{A} \beta$ production (and especially the production of the long $\mathrm{A} \beta$ species) or clearing the toxic oligomeric $\mathrm{A} \beta$ from the brain will make a difference to the progression of the disease. It would be a mistake to refrain from testing the amyloid hypothesis in patients. We risk that a potential good medication is not reaching the clinic because we scientists cannot reach a consensus about the question to what extent in vitro data can be extrapolated to the in vivo situation.

\section{Reference}

[1] M. Bentahir, O. Nyabi, J. Verhamme, A. Tolia, K. Horre, J. Wiltfang, H. Esselmann and B. de Strooper, Presenilin clinical mutations can affect gamma-secretase activity by different mechanisms, J Neurochem 96 (2006), 732-742.

\section{Comment by: Jie Shen, Brigham and Women's Hos- pital, Boston, Massachusetts, USA}

Submitted 11 April 2006

Based on our mouse genetic studies, which showed that conditional inactivation of presenilins in the mouse brain phenocopies the cardinal features of Alzheimer disease, namely dementia and neurodegeneration, I proposed in 2003 that FAD-linked PS mutations may cause the disease via a partial loss-of-function mechanism [1].

The two papers that are being discussed here add to a large number of reports published since 1996 indicating that FAD-linked mutations in presenilins cause partial loss of PS function or $\gamma$-secretase activity [2-10]. Some of these published reports are listed below. Bart De Strooper's paper confirms and extends prior studies from Raphael Kopan's and Alison Goate's laboratories showing reduced activities of mutant presenilins in PS-null MEFs.

\section{References}

[1] C.A. Saura, S.Y. Choi, V. Beglopoulos, S. Malkani, D. Zhang, B.S. Shankaranarayana Rao, S. Chattarji, R.J. Kelleher 3rd, E.R. Kandel, K. Duff, A. Kirkwood and J. Shen, Loss of presenilin function causes impairments of memory and synaptic plasticity followed by age-dependent neurodegeneration, Neuron 42 (2004), 23-36.

[2] D. Levitan, T.G. Doyle, D. Brousseau, M.K. Lee, G. Thinakaran, H.H. Slunt, S.S. Sisodia and I. Greenwald, Assessment of normal and mutant human presenilin function in Caenorhabditis elegans, Proc Natl Acad Sci USA 93 (1996), 14940-14944.

[3] W. Song, P. Nadeau, M. Yuan, X. Yang, J. Shen and B.A. Yankner, Proteolytic release and nuclear translocation of Notch-1 are induced by presenilin-1 and impaired by pathogenic presenilin-1 mutations, Proc Natl Acad Sci USA 96 (1999), 6959-6963.

[4] F. Chen, Y. Gu, H. Hasegawa, X. Ruan, S. Arawaka, P. Fraser, D. Westaway, H. Mount and P. St George-Hyslop, Presenilin 1 mutations activate gamma 42-secretase but reciprocally inhibit epsilon-secretase cleavage of amyloid precursor protein (APP) and S3-cleavage of notch, J Biol Chem 277 (2002), 3652136526.

[5] Y. Qi, M. Morishima-Kawashima, T. Sato, R. Mitsumori and Y. Ihara, Distinct mechanisms by mutant presenilin 1 and 2 leading to increased intracellular levels of amyloid betaprotein 42 in Chinese hamster ovary cells, Biochemistry 42 (2003), 1042-1052.

[6] E.H. Schroeter, M.X. Ilagan, A.L. Brunkan, S. Hecimovic, Y.M. Li, M. Xu, H.D. Lewis, M.T. Saxena, B. de Strooper, A. Coonrod, T. Tomita, T. Iwatsubo, C.L. Moore, A. Goate, M.S. Wolfe, M. Shearman and R. Kopan, A presenilin dimer at the core of the gamma-secretase enzyme: insights from parallel analysis of Notch 1 and APP proteolysis, Proc Natl Acad Sci USA 100 (2003), 13075-13080.

[7] T. Moehlmann, E. Winkler, X. Xia, D. Edbauer, J. Murrell, A. Capell, C. Kaether, H. Zheng, B. Ghetti, C. Haass and H. Steiner, Presenilin-1 mutations of leucine 166 equally affect the generation of the Notch and APP intracellular domains independent of their effect on Abeta 42 production, Proc Natl Acad Sci USA 99 (2002), 8025-8030.

[8] E.S. Walker, M. Martinez, A.L. Brunkan and A. Goate, Presenilin 2 familial Alzheimer's disease mutations result in partial loss of function and dramatic changes in Abeta 42/40 ratios, $J$ Neurochem 92 (2005), 294-301.

[9] R. Siman, A.G. Reaume, M.J. Savage, S. Trusko, Y.G. Lin, R.W. Scott and D.G. Flood, Presenilin-1 P264L knock-in mutation: differential effects on abeta production, amyloid deposition, and neuronal vulnerability, J Neurosci 20 (2000), 8717-8726.

[10] J.C. Wiley, M. Hudson, K.C. Kanning, L.C. Schecterson and M. Bothwell, Familial Alzheimer's disease mutations inhibit gamma-secretase-mediated liberation of beta-amyloid precursor protein carboxy-terminal fragment, J Neurochem 94 (2005), 1189-1201. 


\section{Comment by: Carlos A. Saura, Universitat Autono- ma Barcelona, Barcelona, Spain \\ Submitted 18 April 2006}

The mechanisms by which FAD-linked PS mutations cause memory loss and neurodegeneration are by far unclear. The paper by Bart De Strooper and collaborators supports a large number of publications describing a reduced activity of PS mutations in the cleavage of APP, Notch, and other $\gamma$-secretase substrates, although the same mutations produce an increase of $\mathrm{A} \beta 42 / 40$ ratio. From these studies, it seems clear to me that PS1 and PS2 mutations have different effects on A $\beta 40$ and $\mathrm{A} \beta 42$ generation, although these mutations impair the $\gamma$-cleavage of APP (or its equivalent S3 cleavage of Notch). This suggests that these mutations act on these cleavage events partially through loss-of-function mechanism(s).

However, the most striking evidence for a PS loss-offunction-mediated pathogenic mechanism came from our investigations using brain-specific PS conditional knockout mice ([1]; see Jie Shen's comment). In that study, we showed that loss of PS function over time leads to synaptic dysfunction, neurodegeneration, and memory loss. In support of this partial loss-of-function mechanism, I also recommend reading the recent findings by Hui Zheng's lab [2]. They generated a new mutant PS1 knock-in mouse that harbors a large deletion of the loop domain of PS1, a domain that is dispensable for $\gamma$-secretase activity [3]. Interestingly, the deletion of this domain in the endogenous mouse PS1 gene leads to unchanged $\mathrm{A} \beta 42$, reduced $\mathrm{A} \beta 40$ levels, and increased amyloid plaque deposition. This data demonstrate in vivo that reduction of $\mathrm{A} \beta 40$ levels may cause an exacerbated AD-like pathogenic phenotype.

Furthermore, and as noticed by Drs. Saido and Kumar-Singh, a few PS1 mutations cause frontotemporal dementia with tauopathy in the absence of amyloid plaque deposition [4]. Due to the variety of cellular events affected by PS mutations, maybe it would be more appropriate to describe these PS mutations as "abnormal function" mutations instead of being considered as "gain-" or "loss-of-function" mutants.

\section{References}

[1] C.A. Saura, S.Y. Choi, V. Beglopoulos, S. Malkani, D. Zhang, B.S. Shankaranarayana Rao, S. Chattarji, R.J. Kelleher 3rd, E.R. Kandel, K. Duff, A. Kirkwood and J. Shen, Loss of presenilin function causes impairments of memory and synaptic plasticity followed by age-dependent neurodegeneration, Neuron 42 (2004), 23-36.
[2] Y. Deng, L. Tarassishin, V. Kallhoff, E. Peethumnongsin, L. Wu, Y.M. Li and H. Zheng, Deletion of presenilin 1 hydrophilic loop sequence leads to impaired gamma-secretase activity and exacerbated amyloid pathology, J Neurosci 26 (2006), 38453854.

[3] C.A. Saura, T. Tomita, M. Takahashi, J.Y. Leem, T. Honda, T. Iwatsubo and G. Thinakaran, The non-conserved hydrophilic loop domain of presenilin (PS) is not required for PS endoproteolysis or enhanced A?42 production mediated by familial early-onset Alzheimer's disease-linked PS variants, J Biol Chem 275 (2000), 17136-17142.

[4] M. Hutton, Presenilin mutations associated with frontotemporal dementia, Ann Neurol 55 (2004), 604-606.

Comment by: Todd Golde, Mayo Clinic Jacksonville, Jacksonville, Florida, USA

Submitted 18 April 2006

With respect to Dr. Davies's comments, I think first and foremost we have to consider the fact that presenilin mutations are not the sole genetic cause of AD. The recent finding that APP gene duplications (in the absence of overt trisomy 21) cause AD definitively demonstrates that APP, and hence $\mathrm{A} \beta$ overproduction, drives this disease. The current manuscript shows very nicely that different PS mutants behave differently, but all that cause $\mathrm{AD}$ result in relatively more $\mathrm{A} \beta$ production. Indeed, the really nice feature of this manuscript is that it tells us not all FAD-linked PS mutations are equal in terms of functional effects. Given that the mutations are distributed throughout the molecule, one would not expect them to be.

For some time I have avoided the terms "gain or loss of function" with respect to these mutations, and simply refer to them as mutations that shift function. The manuscript by Bentahir et al. shows this "shift of function" very nicely. It will be an exciting time when we understand at a precise molecular level how the conformation of the PS complex is altered by mutations that shift its function.

Comment by: Matthew Hass ${ }^{\mathrm{a}}$ and Bruce Yankner $^{\mathrm{b}}$

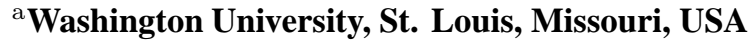
${ }^{\mathrm{b}}$ Harvard Medical School, Boston, Massachusetts, USA

Submitted 24 April 2006

\section{Loss of What?}

These three papers provide convincing evidence that familial PS mutations can reduce total $\mathrm{A} \beta$ produc- 
tion both in vitro and in vivo despite increasing the $\mathrm{A} \beta 42: 40$ ratio, as a result of decreasing absolute levels of $\mathrm{A} \beta 40$. This finding extends our earlier observation that PS1 mutations cause loss of function of $\gamma$ secretase-mediated Notch cleavage and nuclear signaling [1], and raises the intriguing possibility that loss of PS function may contribute to the pathogenesis of AD. But how such a loss of function could contribute to $\mathrm{AD}$, other than just by increasing the $\mathrm{A} \beta 42: 40$ ratio, remains to be determined. Nonetheless, these studies raise a number of interesting questions and possibilities for future investigation.

1. Could $\mathrm{A} \beta 40$ actually be a protective molecule? This question could be addressed by crossing the recent Bri-A $\beta 40$ mouse, which does not have an amyloidogenic phenotype, with the Bri-A $\beta 42$ mice, which develop $\mathrm{A} \beta$ deposits, in order to determine whether $\mathrm{A} \beta 40$ can reduce $\mathrm{A} \beta 42$ deposition or cognitive deficits. This is an important question from a therapeutic standpoint, as $\gamma$-secretase inhibitors that more potently inhibit $\mathrm{A} \beta 40$ than $\mathrm{A} \beta 42$ might increase the $\mathrm{A} \beta 42: \mathrm{A} \beta 40$ ratio, as observed for some PS1 mutations. Thus, these drugs could exacerbate amyloid pathology.

2. Is the decreased generation of the soluble intracellular domains of the myriad of substrates of $\gamma$ secretase relevant to pathogenesis? This hypothesis has gained some credence from the studies of Jie Shen and colleagues on presenilin conditional knockout (PS cKO) mice that exhibit cognitive deficits and marked neurodegeneration, a phenotype that has not been accomplished with APP transgenic mice. The caveat in these studies is that the PS cKO mice represent a complete loss of presenilin function, rather than the partial loss of function presumed to occur in individuals harboring PS mutant alleles. The single PS1 KO mouse has a much milder phenotype. However, it is conceivable that the complete PS knockout accelerates the effects of partial loss of PS function in humans, effects that might take years to become clinically significant.

3. Does partial loss of function associated with presenilin mutations confer increased susceptibility to dementia independently of amyloid deposition? The identification of pathogenic mutations in PS1 that are linked to frontotemporal dementia rather than $\mathrm{AD}$ supports this possibility. AD-causing mutations may be a mix of increased susceptibility to dementia due to loss of presenilin function coupled with an enhanced $\mathrm{A} \beta 42: 40$ ratio, resulting in Alzheimer disease rather than another form of dementia.

For the loss-of-function hypothesis to be considered on par with the amyloid hypothesis, a biological function must be identified that is affected not only by presenilin mutations but also by pathogenic APP mutations. Moreover, a mechanism or pathway needs to be identified that makes sense from the standpoint of neurodegeneration and cognitive impairment. These recent findings should provide an impetus for further research into such a mechanism.

\section{Reference}

[1] W. Song, P. Nadeau, M. Yuan, X. Yang, J. Shen and B.A. Yankner, Proteolytic release and nuclear translocation of Notch-1 are induced by presenilin-1 and impaired by pathogenic presenilin1 mutations, Proc Natl Acad Sci USA 96 (1999), 6959-6963.

Comment by: Philippe Marambaud, The Feinstein Institute for Medical Research, Manhasset, New York, USA

Submitted 25 April 2006

A consensus about the exact molecular mechanism by which PS1 pathogenic mutations affect APP processing in the diseased human brain, or even in cell culture or animal models, seems difficult to reach. This lack of consensus is nicely highlighted in the present forum discussion following Peter Davies's and Gabrielle Strobel's comments.

The debate is about defining the effect of FAD-linked PS1 mutations on the catalytic functions of the protein. Several results support the notion that some of these mutations lead to a severe loss of catalytic function, as clearly shown for the $\gamma$-secretase cleavage of N-cadherin [1], Notch-1 [2-4], and ephrinB2 [5]. A similar apparent loss-of-function mechanism was also reported for APP processing at the $\varepsilon$-cleavage site [6,7], and was recently confirmed by De Strooper's, KumarSingh's, and Van Broeckhoven's groups [8]. Moreover, Hui Zheng and colleagues, in an elegant set of experiments in two independent animal models, have further demonstrated that mutated PS1 promotes amyloid pathology in vivo via a partial loss of $\gamma$-secretase function $[9,10]$.

Several participants in this discussion brought up a strong argument against the extrapolation of this concept in the human brain. It refers to the fact that FAD 
patients carry a wild-type PS1 allele that should fully compensate for any loss of function triggered by the mutated PS1. This argument is supported by the apparent lack of Notch signaling defects in these patients (at least at the developmental stage), and by the normal levels of $\mathrm{A} \beta$ production and absence of amyloid deposition in PS1+/- mice.

Autosomal-dominant inheritance of several diseases can be caused by dominant-negative missense mutations in the causative gene. This is the case in several familial syndromes, including two inherited forms of diabetes caused by mutations in the vasopressinneurophysin II and insulin promoter factor-1 genes. FAD PS1 mutants, by way of physically and/or functionally interacting with the coexpressed wild-type PS1, may similarly act via a dominant-negative mechanism that will prevent compensation by wild-type PS alleles. This is a mechanism that could lead to an overall loss of function. This may explain how introduction of one mutated PS1 allele in Tg2576 mice promotes amyloid deposition via a loss of $\gamma$-secretase function, which is further exacerbated by deletion of the wt PS1 allele [9]. This effect was also apparent from our studies in transfected HEK293 cells expressing PS1 $\Delta$ E9, where the endogenous (cleaved) PS1 was normally expressed but unable to maintain any detectable levels of $\gamma$-secretase cleavage of N-cadherin [1].

In short, FAD PS mutations may act via a targeted dominant-negative mechanism that affects $\gamma$-secretase activity at the $\varepsilon$ and $\gamma 40$ cleavages (over the wild-type allele). This effect might translate into an imbalance in APP processing that can facilitate, to some extent, A $\beta 42$ production (see also comment by Nik Robakis). This could explain how one mutated allele can cause the disease, and why FAD PS mutant expression and PS1 deficiency lead to two clearly distinct pathophysiological conditions.

\section{References}

[1] P. Marambaud, P.H. Wen, A. Dutt, J Shioi, A. Takashima, R. Siman and N.K. Robakis, A CBP binding transcriptional repressor produced by the PS1/epsilon-cleavage of N-cadherin is inhibited by PS1 FAD mutations, Cell 114 (2003), 635-645.

[2] W. Song, P. Nadeau, M. Yuan, X. Yang, J. Shen and B.A. Yankner, Proteolytic release and nuclear translocation of Notch-1 are induced by presenilin-1 and impaired by pathogenic presenilin-1 mutations, Proc Natl Acad Sci USA 96 (1999), 6959-6963.

[3] M. Nakajima, T. Shimizu and T. Shirasawa, Notch-1 activation by familial Alzheimer's disease (FAD)-linked mutant forms of presenilin-1, J Neurosci Res 62 (2000), 311-317.
[4] T. Moehlmann, E. Winkler, X. Xia, D. Edbauer, J. Murrell, A. Capell, C. Kaether, H. Zheng, B. Ghetti, C. Haass and H. Steiner, Presenilin-1 mutations of leucine 166 equally affect the generation of the Notch and APP intracellular domains independent of their effect on Abeta 42 production, Proc Natl Acad Sci USA 99 (2002), 8025-8030.

[5] A. Georgakopoulos, C. Litterst, E. Ghersi, L. Baki, C. Xu, G. Serban and N.K. Robakis, Metalloproteinase/Presenilin1 processing of ephrinB regulates EphB-induced Src phosphorylation and signaling, EMBO J 25 (2006), 1242-1252.

[6] F. Chen, Y. Gu, H. Hasegawa, X. Ruan, S. Arawaka, P. Fraser, D. Westaway, H. Mount and P. St George-Hyslop, Presenilin 1 mutations activate gamma 42 -secretase but reciprocally inhibit epsilon-secretase cleavage of amyloid precursor protein (APP) and S3-cleavage of notch, J Biol Chem 277 (2002), 3652136526.

[7] J.C. Wiley, M. Hudson, K.C. Kanning, L.C. Schecterson and M. Bothwell, Familial Alzheimer's disease mutations inhibit gamma-secretase-mediated liberation of beta-amyloid precursor protein carboxy-terminal fragment, J Neurochem 94 (2005), 1189-1201.

[8] M. Bentahir, O. Nyabi, J. Verhamme, A. Tolia, K. Horre, J. Wiltfang, H. Esselmann and B. de Strooper, Presenilin clinical mutations can affect gamma-secretase activity by different mechanisms, J Neurochem 96 (2006), 732-742.

[9] R. Wang, B. Wang, W. He and H. Zheng, Wild-type presenilin 1 protects against Alzheimer's disease mutation-induced amyloid pathology, J Biol Chem (2006).

[10] Y. Deng, L. Tarassishin, V. Kallhoff, E. Peethumnongsin, L. Wu, Y.M. Li and H. Zheng, Deletion of presenilin 1 hydrophilic loop sequence leads to impaired gamma-secretase activity and exacerbated amyloid pathology, J Neurosci 26 (2006), 3845-3854.

\section{Comment by: Frédéric Checler, Institut de Phar- macologie Moléculaire et Cellulaire, Valbonne, France}

Submitted 26 April 2006

The mechanisms by which mutations on presenilins may trigger or participate to AD pathology is a major issue in the field. The paper by Bart de Strooper's group confirmed that we should better pay attention to the $\mathrm{A} \beta 42$-over- $\mathrm{A} \beta 40$ ratio and suggest that absolute amounts of the two species should be also thoroughly examined. Obviously this paper not only shows that pathogenic mutations could alter overall load of $\mathrm{A} \beta$ but raises many questions about the putative "physiological" role of $\mathrm{A} \beta$. To some extent the paper could be seen as support for the view stating that $\mathrm{A} \beta$ (likely the 40 -amino-acid long) could have protective function.

It should be noted that we previously reported on the first mutation on APP that was associated with an aggressive familial form of AD with about 50 percent reduction in $\mathrm{A} \beta$ [1]. Interestingly, all the reduction could be accounted for a by loss of $\mathrm{A} \beta 40$ while $\mathrm{A} \beta 42$ was not 
affected. Therefore, again, the $\mathrm{A} \beta 42$ versus 40 ratio was drastically increased. However, another interesting aspect was the drastic changes in N-terminally truncated forms of $\mathrm{A} \beta$. Thus, $\mathrm{X}-40$ was not affected while $\mathrm{X}-42$ was increased by several folds. Therefore, perhaps, the ratio of the X-42/X-40 should be also closely examined as a paradigm, and the cell system used in Bentahir's work could be of help.

\section{Reference}

[1] K. Ancolio, C. Dumanchin, H. Barelli, J.M. Warter, A. Brice, D. Campion, T. Frebourg and F. Checler, Unusual phenotypic alteration of beta APP maturation by a new Val715- $>$ Met betaAPP770 mutation responsible for early onset Alzheimer's disease, Proc Natl Acad Sci USA 96 (1999), 4119-4124.

\section{Comment by: Raphael Kopan, Washington Univer-} sity, St. Louis, Missouri, USA

Submitted 2 May 2006

I second Rudy's point: the "gain" seen in the human population is best attributed to change in $\mathrm{A} \beta 40 / 42$ ratio, as many of us have reported in the past. Even biochemical loss-of-function mutations in PS proteins result in altered 40/42 ratio. I will not cite my own or papers from other groups since they have all been mentioned already in this string. Another point against a simple loss of function model is the presence of two PS2 alleles and one PS1 allele with wild-type function in FAD families.

Importantly, we do now know what would be the phenotype in humans with reduced Notch activity, expected from loss of function of $\gamma$-secretase: aortic valve disease [1]. Like AD, AVD is a late-onset condition. Unless a correlation is detected between $\mathrm{AD}$ and aortic valve disease, perhaps we should focus our efforts on allosteric modulation of the ratio as a therapeutic angle.

\section{Reference}

[1] V. Garg, A.N. Muth, J.F. Ransom, M.K. Schluterman, R. Barnes, I.N. King, P.D. Grossfeld and D. Srivastava, Mutations in NOTCH1 cause aortic valve disease, Nature 21 (2005), 180 184.
Comment by: Rudy Tanzi, Massachusetts General Hospital, Charlestown, Massachusetts, USA

Submitted 1 May 2006

From a genetic standpoint, the fact that presenilin and APP mutations are autosomal dominant implies that, ultimately, the etiological effects involve "gain" of function even if from the standpoint of pathogenesis, we observe a chain of "cause and effect" events cycling between "loss" and "gain" of function.

Specifically, 160 different mutations spanning the presenilins most likely compromise the normal function of presenilins, which can be interpreted as "loss" of function in the $\gamma$-secretase complex. However, in the case of APP cleavage, the result is not just impaired production of $\mathrm{A} \beta 40$, but also enhanced production of $\mathrm{A} \beta 42$. The increase in $\mathrm{A} \beta 42$ ("gain" of function) then promotes $\mathrm{A} \beta$ oligomerization ("gain" of function). The "gain" of $\mathrm{A} \beta$ oligomers might then lead to impaired synaptic function and LTP ("loss" of function). Pushing this further, one could argue that if impaired synaptic activity owing to $\mathrm{A} \beta$ oligomers occurs in inhibitory synapses, one might also observe a "loss" of inhibitory synaptic function-the pathogenic chain of cause and effect events can go on and on.

However, it must be emphasized that the Mendelian model for transmission of 180 mutations in both substrate (APP) and enzyme component (presenilins) is autosomal dominant, not recessive. Thus, in the end it must be a "gain of function" event in this chain of cause and effect events that must drive the etiology of AD stemming from these mutations. The mutations in both APP and the presenilins etiologically share in common one known "gain" of function event: increased production $\mathrm{A} \beta 42$ (even if this is ultimately due to "loss" of normal presenilin/ $\gamma$-secretase function).) It is also possible that "loss" of presenilin function also contributes to the disease, but given that this is a dominant disorder, such contributions must be considered as secondary (part of pathogenesis), and not primary (etiological).

Comment by: Rachael Neve, McLean Hospital, Belmont, Massachusetts, USA

Submitted 17 May 2006

Three papers published within the last 2 weeks highlight the potential importance of presenilin and amyloid precursor protein (APP) signaling in the etiology of Alzheimer disease (AD): 
T. Engel, F. Hernandez, J. Avila and J.J. Lucas, Full reversal of Alzheimer's disease-like phenotype in a mouse model with conditional overexpression of glycogen synthase kinase-3, $\mathrm{J} \mathrm{Neu}$ rosci 26 (2006), 5083-5090.

L.E. Doglio, R. Kanwar, G.R. Jackson, M. Perez, J. Avila, C. Dingwall, C.G. Dotti, M.E. Fortini and F. Feiguin, Gamma-cleavage-independent functions of presenilin, nicastrin, and Aph-1 regulate cell-junction organization and prevent tau toxicity in vivo, Neuron 50 (2006), 359-375.

V. Galvan, O.F. Gorostiza, S. Banwait, M. Ataie, A.V. Logvinova, S. Sitaraman, E. Carlson, S.A. Sagi, N. Chevallier, K. Jin, D.A. Greenberg and D.E. Bredesen, Reversal of Alzheimer's-like pathology and behavior in human APP transgenic mice by mutation of Asp664, Proc Natl Acad Sci USA 103 (2006), 7130-7135.

Presenilin is most commonly known as a component of the $\gamma$-secretase complex. It is in this capacity that familial Alzheimer disease (FAD) mutations in presenilin are thought to cause AD neurodegeneration, the idea being that these mutations cause gainof-function changes in $\gamma$-secretase activity that result in increased production and aggregation of amyloid- $\beta$ $(\mathrm{A} \beta)$. However, presenilin has functions that are distinct from its role in the $\gamma$-secretase complex, raising the possibility that loss of these functions may cause at least some of the neurodegeneration and memory loss that occurs in AD. One of the first hints that this may be the case was the finding by the Shen laboratory that presenilin knockout mice exhibit impairments in hippocampal memory and long-term potentiation, which are followed by neurodegeneration and tau hyperphosphorylation [1]. This finding suggested that normally presenilin possesses a neuronal survival function that is lost in these animals.

Within the last 2 months, three papers ([2,3]; KumarSingh et al., Human Mutation, in press) showed, in quick succession, that certain FAD presenilin mutations actually decrease the $\gamma$-secretase activity of this molecule. Moreover, wild-type presenilin, consistent with the notion that it promotes neuronal survival, protects against FAD APP-induced amyloid pathogenesis in transgenic animals [3], whereas presenilin impaired in $\gamma$-secretase activity leads to exacerbated amyloid pathology in FAD APP transgenic animals [4]. These findings suggest that FAD mutations of presenilin may impair its function rather than cause gain-of-function $\gamma$ secretase activity. They also suggest, considered in the context of the Shen laboratory work cited above, that we should be looking at other functions of presenilin besides its $\gamma$-secretase activity to find clues as to how FAD presenilin mutants cause AD neuropathology.

What might these other functions consist of? Work from the Robakis laboratory [5] demonstrated that presenilin inhibits apoptosis by promoting cadherin/phosphatidylinositol-3-kinase (PI3K) association, thereby activating PI3K/Akt cell survival signaling. Presenilin AD mutations interfere with the presenilin-dependent activation of the PI3K/Akt signaling, and this interference results in increased GSK3 activity and in activation of apoptotic caspase-3 [5]. Consistent with the idea that increased GSK3 activity may be important in the development of AD pathology, Lucas et al. and Hernandez et al. demonstrated that transgenic mice overexpressing GSK3 develop AD-like neuropathology; remarkably, they have just shown that this pathology can be reversed by decreasing GSK3 expression to normal levels [6]. This finding is presented in the first of the three papers that are highlighted above.

Such work emphasizes the importance of pursuing research that expands on the PI3K/Akt signaling function of presenilin, and that suggests how impairment of this activity might lead to specific aspects of $\mathrm{AD}$ neurodegeneration $[7,8]$. The second of the three papers highlighted above describes such research. Doglio and coauthors, in an outstanding tour de force, use the power of Drosophila genetics to analyze in detail the in vivo consequences of interfering with functions of components of the $\gamma$-secretase complex that are independent of $\gamma$ cleavage [9]. They demonstrate that two of these components, presenilin and nicastrin, modulate tau-induced neurodegeneration via their activities in the PI3K/Akt/GSK $3 \beta$ phosphorylation pathway; reduction of the levels of these molecules enhances tau toxicity independent of $\gamma$-secretase activity. In addition, Aph-1 suppresses tau hyperphosphorylation via its regulation of aPKC/PAR-1 activity.

These two recent papers build an increasingly strong case for the notion that impairment of presenilin signaling, rather than gain-of-function of its $\gamma$-secretase activity, may be critical for the development of AD neurodegeneration. Does this mean that we should also be looking at alternative functions for the amyloid precursor protein (APP) as well, beyond its role as the source of the amyloid- $\beta$ peptides that accumulate in the brains of patients with AD? Probably. A large body of work, beginning with the prediction by Kang et al. that APP was a type 1 intrinsic membrane protein consistent with the structure of a "cell surface receptor," supports the 
idea that APP is a signaling receptor. The first direct evidence in support of this notion was the finding that the APP cytodomain interacted with the heterotrimeric $\mathrm{G}$ protein Go [10]; independent confirmation of this finding was subsequently published [11]. Since then, a multitude of additional cytosolic proteins that interact with the APP cytodomain have been described [1221], suggesting that APP has versatile signaling roles. Notably, at least one APP signaling pathway that has been identified is independent of $\gamma$-secretase [22]. Of additional interest are two reports indicating that FAD mutations in APP also interfere with PI3K/Akt signaling [23,24].

All but one of the binding proteins for the APP cytodomain interact with APP within the last 31 amino acids of this domain. Why is this significant? For one thing, C31 can be generated from APP by caspase cleavage [25,26]. Furthermore, this cleavage has function significance: Expression of C31 alone has been shown to cause neuronal cell cycle entry and apoptosis [20,26,27]. Most recently, in the third paper highlighted in this commentary, inhibition of C31-producing caspase cleavage of APP prevented the development of AD-like pathology and behavior caused by the Indiana and Swedish FAD mutations of APP [28]. The authors of this paper introduced the D664A mutation (which prevents the generation of C31) into the background of a human APP minigene carrying the K670N/M671L (Swedish) and V717F (Indiana) mutations. Both the original FAD mutant minigene (PDAPP) and also the D664A version of it [PDAPP(D664A)] were expressed in transgenic mice under the control of the PDGF B-chain promoter.

First, the authors determined that the D664A mutation did not alter the net in vivo production of $\mathrm{A} \beta 40$ and $\mathrm{A} \beta 42$ in the brains of the mice, nor did it affect the extent of amyloid plaque deposition in PDAPP(D664A) mice compared to PDAPP mice. However, the D664A mutation did have an effect on neurodegeneration and on behavior. While the PDAPP mice displayed decreased hippocampal presynaptic density number relative to controls at 8-10 months of age, the PDAPP(D664A) were indistinguishable from controls in this parameter. PDAPP mice showed a pronounced increase in GFAP immunoreactivity in the hippocampus by 12 months of age; PDAPP(D664A) mice did not. At 3 months of age, PDAPP mice were found to have a loss in dentate gyrus volume; PDAPP(D664A) mice did not have such a loss. At 12 months of age, PDAPP mice demonstrated learning and spatial impairments; PDAPP(D664A) mice did not. Numbers of prolifer- ating cells present in the subgranular zone of the dentate gyrus were increased in both 3- and 12-month-old PDAPP mice, but were not in PDAPP(D664A) mice of the same age.

From these data, it can be inferred that the mutation Asp664 "rescues" multiple aspects of neuropathology and impaired learning that are normally caused by the Swedish and Indiana mutations in APP. In other words, if C31 cannot be generated, the FAD APP mutations cannot cause certain pathological and behavioral abnormalities. What are the implications of these findings? First of all, note that Asp664 selectively rescues the neurodegeneration and the learning abnormalities of the PDAPP mice without decreasing the production of $\mathrm{A} \beta 40$ or $\mathrm{A} \beta 42$. Thus, the rescue is independent of the production of $\mathrm{A} \beta$. Secondly, the $\mathrm{C} 31$ region of APP encompasses the binding sites for nearly all of the signaling proteins that have been shown to bind to the intracellular domain of APP. The data suggest a scenario in which $\mathrm{C} 31$, when removed from APP, abnormally activates or disrupts signaling pathways mediated by APP. One possibility is that the signaling initiated by interaction of the APP C-terminal domain with signal transduction proteins normally is tightly regulated by binding of ligand(s) to its extracellular domain (variously identified as F-spondin [29], Notch [30,31], TGF- $\beta 2$ [32], and even $\mathrm{A} \beta$ [33,34]). In such a scenario, as suggested by McPhie et al., C31, when not attached to APP, is relieved of the normal constraints imposed on it when the extracellular domain of APP is not occupied by a ligand, and becomes constitutively active or else takes on signaling functions that it does not normally possess. To test the idea that C31 becomes constitutively active, one may ask whether causing APP signaling to become tonically active by other means results in the same consequences for the neuron that expression of $\mathrm{C} 31$ alone does. It was shown by the late Ikuo Nishimoto that exposure of neuronal cells to the antibody $22 \mathrm{C} 11$, raised against the extracellular domain of APP, causes constitutive activation of Go [35], which is known to bind to and be activated by APP $[11,36,37]$. In this context, 22C11 could be considered to be an APP ligand mimetic of sorts. Indeed, sustained exposure of neurons to $22 \mathrm{C} 11$ causes neuronal apoptosis [20,38,39] and cell cycle entry [20] via a signal transduction pathway that is activated by C31 alone [20].

The trio of papers discussed in this commentary, taken together with the body of work preceding them, make the case that presenilin and/or APP signaling is likely to be important in the etiology of AD. Studies that 
delineate the normal signaling pathways mediated by presenilin and APP are to be encouraged, for they are certain to help us understand how signal transduction by these proteins goes awry in AD.

\section{References}

[1] C.A. Saura, S.Y. Choi, V. Beglopoulos, S. Malkani, D. Zhang, B.S. Shankaranarayana Rao, S. Chattarji, R.J. Kelleher, E.R. Kandel, K. Duff, A. Kirkwood and J. Shen, Loss of presenilin function causes impairments of memory and synaptic plasticity followed by age-dependent neurodegeneration, Neuron $\mathbf{4 2}$ (2004), 23-36.

[2] M. Bentahir, O. Nyabi, J. Verhamme, A. Tolia, K. Horre, J. Wiltfang, H. Esselmann, B. de Strooper, Presenilin clinical mutations can affect gamma-secretase activity by different mechanisms, J Neurochem 96 (2006), 732-742.

[3] R. Wang, B. Wang, W. He and H. Zheng, Wild-type presenilin 1 protects against Alzheimer disease mutation-induced amyloid pathology, J Biol Chem 281 (2006), 15330-15336.

[4] Y. Deng, L. Tarassishin, V. Kallhoff, E. Peethumnongsin, L. Wu, Y.M. Li and H. Zheng, Deletion of presenilin 1 hydrophilic loop sequence leads to impaired gamma-secretase activity and exacerbated amyloid pathology, J Neurosci 26 (2006), 3845-3854.

[5] L. Baki, J. Shioi, P. Wen, Z. Shao, A. Schwarzman, M. GamaSosa, R. Neve and N.K. Robakis, PS1 activates PI3K thus inhibiting GSK-3 activity and tau overphosphorylation: effects of FAD mutations, EMBO J 23 (2004), 2586-2596.

[6] T. Engel, F. Hernández, J. Avila and J.J. Lucas, Full reversal of Alzheimer's disease-like phenotype in a mouse model with conditional overexpression of glycogen synthase kinase-3, $J$ Neurosci 26 (2006), 5083-5090.

[7] J.J. Lucas, F. Hernández, P. Gómez-Ramos, M.A. Morán, R. Hen and J. Avila, Decreased nuclear beta-catenin, tau hyperphosphorylation and neurodegeneration in GSK-3beta conditional transgenic mice, EMBO J 20 (2001), 27-39.

[8] F. Hernández, J. Borrell, C. Guaza, J. Avila and J.J. Lucas, Spatial learning deficit in transgenic mice that conditionally over-express GSK-3beta in the brain but do not form tau filaments, J Neurochem 83 (2002), 1529-1533.

[9] L.E. Doglio, R. Kanwar, G.R. Jackson, M. Perez, J. Avila, C. Dingwall, C.G. Dotti, M.E. Fortini and F. Feiguin, gammacleavage-independent functions of presenilin, nicastrin, and Aph-1 regulate cell-junction organization and prevent tau toxicity in vivo, Neuron 50 (2006), 359-375.

[10] I. Nishimoto, T. Okamoto, Y. Matsuura, S. Takahashi, T. Okamoto, Y. Murayama and E. Ogata, Alzheimer amyloid protein precursor complexes with brain GTP-binding protein G(o), Nature 362 (1993), 75-79.

[11] E. Brouillet, A. Trembleau, D. Galanaud, M. Volovitch, C. Bouillot, C. Valenza, A. Prochiantz and B. Allinquant, The amyloid precursor protein interacts with Go heterotrimeric protein within a cell compartment specialized in signal transduction, J Neurosci 19 (1999), 1717-1727.

[12] N. Chow, J.R. Korenberg, X.N. Chen and R.L. Neve, APP$\mathrm{BP} 1$, a novel protein that binds to the carboxyl-terminal region of the amyloid precursor protein, J Biol Chem 271 (1996), 11339-11346.

[13] J.P. Borg, J. Ooi, E. Levy and B. Margolis, The phosphotyrosine interaction domains of X11 and FE65 bind to distinct sites on the YENPTY motif of amyloid precursor protein, $\mathrm{Mol}$ Cell Biol 16 (1996), 6229-6241.

[14] M. Trommsdorff, J.P. Borg, B. Margolis and J. Herz, Interaction of cytosolic adaptor proteins with neuronal apolipoprotein E receptors and the amyloid precursor protein, J Biol Chem 273 (1998), 33556-33560.

[15] S. Tomita, T. Ozaki, H. Taru, S. Oguchi, S. Takeda, Y. Yagi, S. Sakiyama, Y. Kirino and T. Suzuki, Interaction of a neuronspecific protein containing PDZ domains with Alzheimer's amyloid precursor protein, J Biol Chem 274 (1999), 22432254.

[16] H. Tanahashi and T. Tabira, X11L2, a new member of the X11 protein family, interacts with Alzheimer's beta-amyloid precursor protein, Biochem Biophys Res Commun 255 (1999), 663-667.

[17] X. Cao and T.C. Südhof, A transcriptionally [correction of transcriptively] active complex of APP with Fe65 and histone acetyltransferase Tip60, Science 293 (2001), 115-120.

[18] S. Matsuda, T. Yasukawa, Y. Homma, Y. Ito, T. Niikura, T. Hiraki, S. Hirai, S. Ohno, Y. Kita, M. Kawasumi, K. Kouyama, T. Yamamoto, J.M. Kyriakis and I. Nishimoto, c-Jun $\mathrm{N}$-terminal kinase (JNK)-interacting protein-1b/islet-brain-1 scaffolds Alzheimer's amyloid precursor protein with JNK, $J$ Neurosci 21 (2001), 6597-6607.

[19] H. Taru, K. Iijima, M. Hase, Y. Kirino, Y. Yagi and T. Suzuki, Interaction of Alzheimer's beta -amyloid precursor family proteins with scaffold proteins of the JNK signaling cascade, J Biol Chem 277 (2002), 20070-20078.

[20] D.L. McPhie, R. Coopersmith, A. Hines-Peralta, Y. Chen, K.J. Ivins, S.P. Manly, M.R. Kozlowski, K.A. Neve and R.L. Neve, DNA synthesis and neuronal apoptosis caused by familial Alzheimer disease mutants of the amyloid precursor protein are mediated by the p 21 activated kinase PAK3, J Neurosci $\mathbf{2 3}$ (2003), 6914-6927.

[21] H. Inomata, Y. Nakamura, A. Hayakawa, H. Takata, T. Suzuki, K. Miyazawa and N. Kitamura, A scaffold protein JIP-1b enhances amyloid precursor protein phosphorylation by JNK and its association with kinesin light chain 1, J Biol Chem 278 (2003), 22946-22955.

[22] M.R. Hass and B.A. Yankner, A \{gamma $\}$-secretaseindependent mechanism of signal transduction by the amyloid precursor protein, J Biol Chem 280 (2005), 36895-36904.

[23] J. Ryder, Y. Su and B. Ni, Akt/GSK3beta serine/threonine kinases: evidence for a signalling pathway mediated by familial Alzheimer's disease mutations, Cell Signal 16 (2004), 187-200.

[24] T. Kashour, T. Burton, A. Dibrov and F.M. Amara, Late Simian virus 40 transcription factor is a target of the phosphoinositide 3-kinase/Akt pathway in anti-apoptotic Alzheimer's amyloid precursor protein signalling, Biochem J 370 (2003), 10631075.

[25] F.G. Gervais, D. Xu, G.S. Robertson, J.P. Vaillancourt, Y. Zhu, J. Huang, A. LeBlanc, D. Smith, M. Rigby, M.S. Shearman, E.E. Clarke, H. Zheng, L.H. van der Ploeg, S.C. Ruffolo, N.A. Thornberry, S. Xanthoudakis, R.J. Zamboni, S. Roy and D.W. Nicholson, Involvement of caspases in proteolytic cleavage of Alzheimer's amyloid-beta precursor protein and amyloidogenic A beta peptide formation, Cell 97 (1999), 395-406.

[26] D.C. Lu, S. Rabizadeh, S. Chandra, R.F. Shayya, L.M. Ellerby, X. Ye, G.S. Salvesen, E.H. Koo and D.E. Bredesen, A second cytotoxic proteolytic peptide derived from amyloid beta-protein precursor, Nat Med 6 (2000), 397-404.

[27] Y. Chen, W. Liu, D.L. McPhie, L. Hassinger and R.L. Neve, APP-BP1 mediates APP-induced apoptosis and DNA synthe- 
sis and is increased in Alzheimer's disease brain, J Cell Biol 163 (2003), 27-33.

[28] V. Galvan, O.F. Gorostiza, S. Banwait, M. Ataie, A.V. Logvinova, S. Sitaraman, E. Carlson, S.A. Sagi, N. Chevallier, K. Jin, D.A. Greenberg and D.E. Bredesen, Reversal of Alzheimer's-like pathology and behavior in human APP transgenic mice by mutation of Asp664, Proc Natl Acad Sci USA 103 (2006), 7130-7135.

[29] A. Ho and T.C. Südhof, Binding of F-spondin to amyloidbeta precursor protein: a candidate amyloid-beta precursor protein ligand that modulates amyloid-beta precursor protein cleavage, Proc Natl Acad Sci USA 101 (2004), 2548-2553.

[30] S.Y. Oh, A. Ellenstein, C.D. Chen, J.D. Hinman, E.A. Berg, C.E. Costello, R. Yamin, R.L. Neve and C.R. Abraham, Amyloid precursor protein interacts with notch receptors, $\mathrm{J} \mathrm{Neu}$ rosci Res 82 (2005), 32-42.

[31] A. Fassa, P. Mehta and S. Efthimiopoulos, Notch 1 interacts with the amyloid precursor protein in a Numb-independent manner, J Neurosci Res 82 (2005), 214-224.

[32] Y. Hashimoto, T. Chiba, M. Yamada, M. Nawa, K. Kanekura, H. Suzuki, K. Terashita, S. Aiso, I. Nishimoto and M. Matsuoka, Transforming growth factor beta2 is a neuronal deathinducing ligand for amyloid-beta precursor protein, Mol Cell Biol 25 (2005), 9304-9317.

[33] A. Lorenzo, M. Yuan, Z. Zhang, P.A. Paganetti, C. SturchlerPierrat, M. Staufenbiel, J. Mautino, F.S. Vigo, B. Sommer and B.A. Yankner, Amyloid beta interacts with the amyloid precursor protein: a potential toxic mechanism in Alzheimer's disease, Nat Neurosci 3 (2000), 460-464.

[34] G.M. Shaked, M.P. Kummer, D.C. Lu, V. Galvan, D.E. Bredesen and E.H. Koo, Abeta induces cell death by direct interaction with its cognate extracellular domain on APP (APP 597-624), FASEB J 20 (2006), 1254-1256.

[35] T. Okamoto, S. Takeda, Y. Murayama, E. Ogata and I. Nishimoto, Ligand-dependent $\mathrm{G}$ protein coupling function of amyloid transmembrane precursor, J Biol Chem 270 (1995), 42054208.

[36] J. Kang, H.G. Lemaire, A. Unterbeck, J.M. Salbaum, C.L. Masters, K.H. Grzeschik, G. Multhaup, K. Beyreuther and B. Müller-Hill, The precursor of Alzheimer's disease amyloid A4 protein resembles a cell-surface receptor, Nature 325 (1987), 733-736.

[37] I. Nishimoto, T. Okamoto, Y. Matsuura, S. Takahashi, T. Okamoto, Y. Murayama and E. Ogata, Alzheimer amyloid protein precursor complexes with brain GTP-binding protein G(o), Nature 362 (1993), 75-79.

[38] H. Sudo, H. Jiang, T. Yasukawa, Y. Hashimoto, T. Niikura, M. Kawasumi, S. Matsuda, Y. Takeuchi, S. Aiso, M. Matsuoka, Y. Murayama and I. Nishimoto, Antibody-regulated neurotoxic function of cell-surface beta-amyloid precursor protein, $\mathrm{Mol}$ Cell Neurosci 16 (2000), 708-723.

[39] T.T. Rohn, K.J. Ivins, B.A. Bahr, C.W. Cotman and D.H. Cribbs, A monoclonal antibody to amyloid precursor protein induces neuronal apoptosis, J Neurochem 74 (2000), 23312342 .

\section{Comment by: Peter Davies, Albert Einstein College of Medicine, Bronx, New York, USA}

Submitted 19 May 2006

It is clear from the responses to our original posting that many people recognize that the mechanism by which presenilin mutations cause Alzheimer disease may be more complicated than a simple increase in $\mathrm{A} \beta$ production. If this is all we have achieved, I will be happy. The situation in the brain of a patient with a presenilin 1 mutation is complicated by the presence of a single mutant allele, with a normal allele of PS1 and two normal alleles of PS2. In a paper published just after our posting, Deng et al. reported on the kind of model that some of commentators suggested should be made: a knock-in mutation of PS1 [1]. These authors report results entirely consistent with those of De Strooper's group and Kumar-Singh et al. A decrease in $\mathrm{A} \beta 40$ was found, with little or no effect on $\mathrm{A} \beta 42$, resulting in an overall reduction in $\mathrm{A} \beta$ levels with an altered 40/42 ratio. Deng et al. expected that the reduced APP processing would be reflected in a reduced amyloid deposition when the PS1 knock-in mutants were crossed with the Tg2576 amyloid depositing mice. The opposite result was found: Despite the reduced A $\beta 40$ and unchanged $\mathrm{A} \beta 42$ levels, significantly more plaques accumulated at all of the four ages examined. Clearly, the level of $\mathrm{A} \beta$ did not determine the extent of amyloid deposition. So what does? The ratio of $\mathrm{A} \beta 40$ to $\mathrm{A} \beta 42$ ? The decrease in $\mathrm{A} \beta 40$ - or some other aspect of defective $\gamma$-secretase processing of APP or perhaps another substrate? If it is really the ratio of $\mathrm{A} \beta 40$ to $\mathrm{A} \beta 42$ that is so critical, what is the mechanism that is so sensitive to this change? The number and range of responses to this discussion suggest that workers in this field have identified questions that need answers, and we hope the posting has stimulated further thoughtful work in this area.

\section{Reference}

[1] Y. Deng, L. Tarassishin, V. Kallhoff, E. Peethumnongsin, L. Wu, Y.M. Li and H. Zheng, Deletion of Presenilin 1 Hydrophilic Loop Sequence Leads to Impaired gamma-secretase Activity and Exacerbated Amyloid Pathology, J Neurosci 26 (2006), 3854 .

Comment by: Vincent Marchesi, Yale University School of Medicine, New Haven, Connecticut, USA Submitted 24 May 2006

Peter Davies was too modest to proclaim, as he did in his closing comment, that he would be happy if many people recognized that the mechanisms by which presenilin mutations cause Alzheimer disease may be 
more complicated than the simple increase in $\mathrm{A} \beta$ production. Indeed, this interesting series of exchanges has accomplished much more than that.

First, the almost mythical hold that the $\mathrm{A} \beta 42 / 40$ ratio has had on the thinking of even well-informed investigators has now been exposed for what it is, a complicated consequence of many poorly understood proteolytic processes that may be more artifactual than revealing. The work of De Strooper and others shows that the contributions that presenilin mutations make to the levels of both $\mathrm{A} \beta 40$ and $\mathrm{A} \beta 42$ are too unpredictable to explain in a coherent way how any of the mutations contribute to the disease process.

Moreover, they also call into question, indirectly, the oft repeated claim that the $\mathrm{A} \beta 42$ forms are the most toxic of the two. It is true that many in-vitro experiments suggest that the $\mathrm{A} \beta 42$ peptides may be more amyloidogenic, but the significance of these findings has always relied on increased $\mathrm{A} \beta 42 / 40$ ratios as being pathogenic, and if these are not reliable guides, as these latest studies imply, the relevance of amyloidogenesis to the early causes of dementia needs to be re-evaluated. I'm not suggesting that $\mathrm{A} \beta 42$ is not toxic, but one has to wonder why there is still no consensus as to how any of the $\mathrm{A} \beta \mathrm{s}$ affect neuronal function. What's more, the recent studies showing that the $\varepsilon$ cleavage precedes the $\gamma$ cleavages imply that much larger forms of the transmembrane segment of APP exist within the lipid bilayer, at least transiently. Could these larger peptides, or hydrophobic fragments of them, affect intramembranous functions?

These uncertainties lead to a deeper question: How do we evaluate animal models that are most relevant to an understanding of the primary mechanisms that lead to Alzheimer's-type dementia? A similar question confronts those, like De Strooper, who advocate applying promising therapeutic ideas directly to patients, a position I personally support. How will we measure the relevance of models and the impact of therapies? It is possible to measure levels of different forms of $\mathrm{A} \beta$ peptides in blood, cerebrospinal fluid, or even brain tissue. But will this lead to an understanding of what might be happening at specific vulnerable sites in the brain, such as, for example, the postsynaptic segments of hippocampal synapses? More focused approaches are clearly needed.

But those who suggest that these revelations cast a dark shadow on the amyloid hypothesis are jumping way ahead of the available data. As De Strooper points out, it would be foolish and irresponsible to ignore the many compelling connections between APP and the different $\mathrm{A} \beta$ peptides with the Alzheimer syndrome. A hint of the exciting prospects that lie ahead, linking $\mathrm{A} \beta$ peptides to neuronal dysfunction, comes from results of recent studies described by Rachael Neve in her May 17 posting. Although not directly relevant to the presenilin mutations question, studies are described in which manipulations of the processing of APP lead to massive overproduction of $\mathrm{A} \beta$ in animals that show little neuronal dysfunction. These results suggest that $\mathrm{A} \beta$-related peptides can affect neuronal functions independent of their ability to polymerize into oligomers or large fibrils. These findings amplify other recent publications that report increased levels of $\mathrm{A} \beta$ peptides as a function of normal neuronal activity. The fact that $\mathrm{A} \beta$ peptides might have a normal physiological function has always been a tantalizing prospect. Now it's time to take it seriously.

\section{Comment by: Bart De Strooper, K.U. Leuven, Leu- ven, Belgium}

Submitted 24 May 2006

It was a great idea to have this discussion online. Different views have confronted each other in a friendly way, and I think the conclusion of the debate is indeed that no simple answer is available at this moment. We clearly need further understanding of the biophysics of the amyloid peptide, of APP function, and of structure and biology of the presenilin/ $\gamma$-secretase complex.

What strikes me most is that it becomes more and more clear that we know too little about the normal function of all of these molecules, and I would stress that we need to look more to their activity in physiologically relevant conditions. I agree with Peter that knock-in models are crucial in that regard.

\section{Comment by: Rudy Tanzi, Massachusetts General Hospital, Charlestown, Massachusetts, USA} Submitted 30 May 2006

Human genetics clearly informs us that more than 150 FAD mutations in APP and the presenilins serve to increase the $\mathrm{A} \beta 42: \mathrm{A} \beta 40$ ratio. Genetics also tells us that it is not absolute $\mathrm{A} \beta$ levels, but the stoichiometric mixture of $\mathrm{A} \beta 42$ and $\mathrm{A} \beta 40$ generated that matters most with regard to etiology and pathogenesis of AD. When $\mathrm{A} \beta 42$ levels become too high, relative to $\mathrm{A} \beta 40$, pre-plaque, neurotoxic $\mathrm{A} \beta$ oligomers are more likely. 
The 42:40 ratio can be increased by elevated generation of $\mathrm{A} \beta 42$, or in cases of loss-of-function of $\gamma$ secretase, e.g. owing to presenilin mutations, due to decreased production of $\mathrm{A} \beta 40.150$ fully penetrant FAD mutations argue that increased 42:40 ratio is the only consistent gain of function event in the autosomal dominant form of this disease, and it is sufficient to lead to onset of AD, usually under 60 years old. Thus, more investigation and drug discovery need to focus on the A $\beta$ 42:40 ratio, itself. Human genetics dictates that if we simply reverse the $42: 40$ ratio (e.g. by decreasing 42 or perhaps, even, increasing 40), you may be able to prevent or treat FAD and other forms of AD. In agreement with Peter, knock-ins of FAD mutants will be invaluable for this purpose.

\section{Comment by: Fred Van Leuven, Experimental Ge- netics Group, Leuven, Belgium \\ Submitted 1 June 2006}

One could fill many more pages with discussions on this topic, pro and con the different theses. It strikes me that arguments / convictions / hypotheses / beliefs that I read here over the last weeks all appeared too familiar. AD-researchers seem to forget even faster than their subjects!

Despite the many mutations found, mutant PS1 is NOT a typical cause of AD. Both Ab40 and 42, but also $\beta$-stubs and other functions (or roles) of APP and PS1 need to be taken up in the overall equation. That is the "basic" science that underpins knowledge of AD pathology. AD is the sign-post offered by nature to draw our attention to important molecules and their functions - but $\mathrm{AD}$ itself is not a fundamental scientific project.

Back to the $\mathrm{A} \beta$ discussion: In the absence of proof to the contrary, I maintain that $\mathrm{A} \beta 42$, besides 40 , but also the entire series from 37 to 43, are byproducts of APP processing for whose disposal an ageing brain has lost - or not yet found - a solution.

Since late-onset and sporadic AD can also be due to overexpression of APP by gene duplication or promoter mutations or polymorphisms, loss of Ab40 does no appear as the primary problem in AD.

I suggest that we continue to test the Ab42/40 ratio as our working hypothesis until hard evidence in vivo proves it wrong.
Comment by: Sanjay W. Pimplikar, Case Western Reserve University, Cleveland, Ohio, USA

Submitted 6 June 2006

From this debate, it is becoming apparent that the 42:40 ratio hypothesis (increased $\mathrm{Ab} 42 / 40$ ratio as being pathogenic) is gaining favor. If so, there must be more to it than meets the eye. Bentahir et al. show that the PS2 N141I mutation had the highest 42:40 ratio (Fig. 4) and yet the mean age at onset was the slowest (Table 1).

\section{Comment by: Rudy Tanzi, Massachusetts General Hospital, Charlestown, Massachusetts, USA} Submitted 11 June 2006

In response to Dr. Pimplikar: With regard to effects of the presenilin 2 (PS2)-N141I FAD mutation [1] as measured in transfected cells overexpressing the mutant gene [2], it's important to consider that, in vivo, presenilin 2 expression is much lower than that of presenilin 1 in brain. Thus, under physiological conditions, the effects of the N141I mutation on $\mathrm{A} \beta 42: \mathrm{A} \beta 40$ ratio may not be as robust as in transfected cells expressing non-physiological levels of mutant PS2. If the ratio were indeed on the high end of the spectrum for FAD mutations in vivo (in patients' brains), while onset is relatively late, the ratio hypothesis would have to be reassessed. I don't know if anyone has ever looked at the actual $\mathrm{A} \beta 42: \mathrm{A} \beta 40$ ratio in the brain of a PS2-N141I mutation carrier.

\section{References}

[1] E. Levy-Lahad, W. Wasco, P. Poorkaj, D.M. Romano, J.M. Oshima, W.H. Pettingell, C. Yu, P.D. Jondro, S.D. Schmidt, K. Wang, A.C. Crowley, Y-H. Fu, S.Y. Guenette, D. Galas, E. Nemens, E.M. Wijsman, T.D. Bird, G.D. Schellenberg and R.E. Tanzi, Candidate gene for the chromosome 1 familial Alzheimer's disease locus, Science 269 (1995), 973-977.

[2] T.-W. Kim, W.H. Pettingell, Y.K. Jung, D.M. Kovacs and R.E. Tanzi, Alternative cleavage of Alzheimer-associated presenilins during apoptosis by a caspase-3 family protease, Science $\mathbf{2 7 7}$ (1997), 373-376. 
Comment by: Samir Kumar-Singh, University of Antwerp, VIB (Flanders Insitute for Biotechnology), Antwerp, Belgium

Submitted 11 April 2006

Drs. Davis, De Strooper, and Gabrielle Strobel have done a superb job in taking the initiative to bring this important discussion on our forum. The contributors raised several important points:

1. Dr. Saido noted that not all PS mutations cause FAD. Indeed, the first type of PS mutations are FAD-linked (and although didactic, I agree we should stick to this terminology). FAD-linked PS mutations are now bunched together - those that show additional phenotypes, that is, spastic paraparesis and those that do not - but at some point we may also have to make a distinction between them. The second type of PS mutations do not deposit $\mathrm{A} \beta$ in brain, have a clinical picture of FTD, and at least one mutation is linked to Pick's disease [1], but how this happens remains elusive. The third type are the "innocent" polymorphisms, though some of them keep reappearing in the clinics in different genetic backgrounds (i.e., E318G; Van Broeckhoven et al., unpublished data), and it could be that some of them require a second hit to have an effect.

2. While the readout for different FAD mutations in studies utilizing PS - / - fibroblasts is straightforward [2], things are more complicated when using human fibroblasts, although these have their own advantages [3]. A key argument is that presence of endogenous intact PS mimics the human situation where only one allele is affected; this is important for studies investigating the relationships between individual $\mathrm{A} \beta 40$ or $\mathrm{A} \beta 42$ levels, or $\mathrm{A} \beta 42: \mathrm{A} \beta 40$ (ratio) and disease severity. The relevance of this is reaffirmed in the latest papers from Hui Zheng's lab showing that in mice coexpressing APP/Sw, wild-type PS1 abolishes the amyloid-depositing potential of a mutant FAD PS1 knock-in [4]. This paper also showed that 50 percent PS1 dosage results in a small but significant decrease in both $\mathrm{A} \beta 40$ and $\mathrm{A} \beta 42$ despite being an in vivo situation dependent on clearance.

3. We increasingly believe that lowered A $\beta 40$ contributes to amyloidosis and AD. While there is plenty of supporting in vitro and in vivo (mice) data, support for human disease comes from the Austrian APP mutation (APP T714I [5]). This mutation has a very early age of onset [6], and one of the highest $\mathrm{A} \beta 42: \mathrm{A} \beta 40$ ratios recorded amongst a panel of APP $\gamma$-secretase site mutations was not due to an exceptional increase in $\mathrm{A} \beta 42$, but to a drastic decrease in $\mathrm{A} \beta 40$ in vitro (60-80 percent, depending on the type of cells analyzed) [5,7]. This was accompanied by almost absent $\mathrm{A} \beta 40$ in brain. It is possible that other genetic factors are responsible for this phenotype in this family, but in vivo modeling experiments have shown that despite a subphysiological mutant APP expression, brain sizes for Austrian APP mice are significantly reduced on volumetric MRI, compared to similar APP/Wt expression [8].

4. Having been unable to detect any increase in A $\beta 42$ for half of the mutations in our study was disconcerting. However, unpublished data from Dr. Robakis's group (where, again, half of the mutations examined did not increase $\mathrm{A} \beta 42$ ), and also in vivo mice data showing accelerated pathology in absence of any increased A $\beta 42$ [4] make me think that somehow, without understanding fully, we had always been doing the right thing measuring the $\mathrm{A} \beta 42: \mathrm{A} \beta 40$ ratio. We would welcome having these data further confirmed by other labs, especially for the same mutations. Even so, the fact that we identify the correlation of A $\beta 42$ :A $\beta 40$ with onset of clinical symptomatology [3], together with another recent paper from Dr. Hartmann's group showing this correlation [9], suggests that all this could be clinically relevant either as a qualitative gain of $\mathrm{A} \beta 42$ function or some loss of function closely linked to the $\mathrm{A} \beta 42: \mathrm{A} \beta 40$ ratio.

\section{References}

[1] B. Dermaut, S. Kumar-Singh, S. Engelborghs, J. Theuns, R. Rademakers, J. Saerens, B.A. Pickut, K. Peeters, M. van den Broeck, K. Vennekens, S. Claes, M. Cruts, P. Cras, J.J. Martin, C. van Broeckhoven and P.P. de Deyn, A novel presenilin 1 mutation associated with Pick's disease but not beta-amyloid plaques, Ann Neurol 55 (2004), 617-626.

[2] M. Bentahir, O. Nyabi, J. Verhamme, A. Tolia, K. Horre, J. Wiltfang, H. Esselmann and B. de Strooper, Presenilin clinical mutations can affect gamma-secretase activity by different mechanisms, J Neurochem 96 (2006), 732-742.

[3] S. Kumar-Singh, J. Theuns, B. van Broeck, D. Pirici, K. Vennekens, E. Corsmit, M. Cruts, B. Dermaut, R. Wang, and C. van Broeckhoven, Clinically aggressive behavior of familial Alzheimer's disease caused by presenilin mutations correlates with both increased A $\beta 42$ and decreased A $\beta 40$, Hum Mutat (in press). 
[4] R. Wang, B. Wang, W. He and H. Zheng, Wild-type presenilin 1 protects against Alzheimer's disease mutation-induced amyloid pathology, J Biol Chem 281 (2006), 15330-15336.

[5] S. Kumar-Singh, C. De Jonghe, M. Cruts, R. Kleinert, R. Wang, M. Mercken, B. de Strooper, H. Vanderstichele, A. Lofgren, I. Vanderhoeven, H. Backhovens, E. Vanmechelen, P.M. Kroisel and C. van Broeckhoven, Nonfibrillar diffuse amyloid deposition due to a gamma(42)-secretase site mutation points to an essential role for $\mathrm{N}$-truncated A beta(42) in Alzheimer's disease, Hum Mol Genet 9 (2000), 2589-2598.

[6] T. Edwards-Lee, J.M. Ringman, J. Chung, J. Werner, A. Morgan, P. St George Hyslop, P. Thompson, R. Dutton, A. Mlikotic, E. Rogaeva and J. Hardy, An African American family with early-onset Alzheimer disease and an APP (T714I) mutation, Neurology 64 (2005), 377-379.

[7] C. De Jonghe, C. Esselens, S. Kumar-Singh, K. Craessaerts,
S. Serneels, F. Checler, W. Annaert, C. van Broeckhoven and B. de Strooper, Pathogenic APP mutations near the gammasecretase cleavage site differentially affect Abeta secretion and APP C-terminal fragment stability, Hum Mol Genet 10 (2001), 1665-1671.

[8] B. van Broeck, G. Vanhoutte, D. Pirici, D. van Dam, H. Wils, I. Cuijt, K. Vennekens, M. Zabielski, A. Michalik, J. Theuns, P.P. de Deyn, A. van der Linden, C. van Broeckhoven and S. Kumar-Singh, Intraneuronal amyloid beta and reduced brain volume in a novel APP T714I mouse model for Alzheimer's disease, Neurobiol Aging (2006).

[9] M. Duering, M.O. Grimm, H.S. Grimm, J. Schroder and T. Hartmann, Mean age of onset in familial Alzheimer's disease is determined by amyloid beta 42, Neurobiol Aging 26 (2005), $785-788$. 